\title{
Regulation of miRNA-146a and miRNA-150 Levels by Celecoxib in Premalignant Lesions of K14-HPV16 Mice
}

\author{
RUI M. GIL DA COSTA ${ }^{1,2,3^{*}}$, RITA ARAÚJO ${ }^{1,4^{*}}$, JOANA M.O. SANTOS ${ }^{1,4}$, \\ MARA FERNANDES ${ }^{1,5,6}$, TIAGO NETO ${ }^{1,3,4}$, HUGO SOUSA ${ }^{1,7}$, JOANA RIBEIRO $^{1,7}$, \\ MARGARIDA M.S.M. BASTOS ${ }^{2}$, PAULA A. OLIVEIRA ${ }^{3,8}$, DIOGO CARMO ${ }^{9}$, \\ FÁTIMA CASACA ${ }^{9}$, SANDRA SILVA ${ }^{9}$, CARLOS LOPES $^{10}$ and RUI MEDEIROS ${ }^{1,4,6,7,11}$ \\ ${ }^{1}$ Molecular Oncology and Viral Pathology Group, IPO-Porto Research Center (CI-IPOP), \\ Portuguese Institute of Oncology of Porto (IPO-Porto), Porto, Portugal; \\ ${ }^{2}$ LEPABE, Faculty of Engineering, University of Porto, Porto, Portugal; \\ ${ }^{3}$ Center for the Research and Technology of Agro-Environmental and Biological Sciences (CITAB), \\ University of Tras-os-Montes and Alto Douro (UTAD), Vila Real, Portugal; \\ ${ }^{4}$ ICBAS, Abel Salazar Institute for the Biomedical Sciences, University of Porto, Porto, Portugal; \\ ${ }^{5}$ FMUP, Faculty of Medicine, University of Porto, Porto, Portugal; \\ ${ }^{6}$ LPCC, Research Department Portuguese League Against Cancer (Liga Portuguesa \\ Contra o Cancro-Nucleo Regional do Norte), Porto, Portugal; \\ ${ }^{7}$ Virology Service, Portuguese Institute of Oncology of Porto, Porto, Portugal; \\ ${ }^{8}$ Veterinary Sciences Department, University of Tras-os-Montes and Alto Douro (UTAD), Vila Real, Portugal; \\ ${ }^{9}$ Botelho Moniz Análises Clínicas (BMAC), Porto, Portugal; \\ ${ }^{10}$ Experimental Pathology and Therapeutics Group, IPO-Porto Research Center (CI-IPOP), \\ Portuguese Institute of Oncology of Porto (IPO-Porto), Porto, Portugal; \\ ${ }^{11}$ CEBIMED, Faculty of Health Sciences, Fernando Pessoa University, Porto, Portugal
}

\begin{abstract}
Background/Aim: Human papillomavirus type 16 (HPV16) induces various types of cancer in several locations. Microenvironmental microRNAs (miRNAs) such as miRNA-146a and miRNA-150 regulate cancer-associated inflammation and are involved in HPV-induced carcinogenesis. We studied the effects of celecoxib on the expression of these two miRNAs in HPV16-induced lesions. Materials and Methods: Female transgenic $\left(H P V 16^{+-}\right)$and wild-type (HPV16-/-) mice were administered $75 \mathrm{mg} / \mathrm{kg} /$ day celecoxib orally (treatment groups) or placebo (control groups) for four weeks. Skin samples were classified histologically, or used for miRNA analysis by quantitative real-time PCR. Results: HPV16 ${ }^{+/-}$mice showed higher miRNA-146a and miRNA-150 expression levels compared to
\end{abstract}

*These authors contributed equally to this study.

Correspondence to: Rui M. Gil da Costa, LEPABE, Faculty of Engineering, University of Porto, Rua Dr. Roberto Frias s/n, 4200465 Porto, Portugal. Tel: +351 225081687, Fax: +351 225081440, e-mail: rmcosta@fe.up.pt

Key Words: HPV16, inflammation, miRNAs, celecoxib, carcinogenesis. wild-type animals. Celecoxib further increased miRNA-150 $(p<0.05)$ and miRNA-146a levels in treated animals. Celecoxib-treated HPV16 ${ }^{+-}$animals also showed reduced incidence of epidermal dysplasia and reduced inflammation, compared to untreated mice. Conclusion: In this model, celecoxib may be able to regulate tumour-associated inflammation, through mechanisms involving the regulation of miRNA-146a and miRNA-150.

Cancer of the uterine cervix, as well as the anus and some other locations is associated with infection by high-risk human papillomavirus (HPV). Most viral infections are quickly cleared but long-term viral persistence is required for tumor initiation and progression. Thus, evading the immune system is essential for cancer development (1). In fact, HPV possesses multiple mechanisms that modulate the host's innate and adaptive immune responses, and facilitate carcinogenesis (2). HPV-induced lesions are often associated with chronic inflammatory phenomena which are thought to enhance tumour progression (3). Such inflammatory processes are partially regulated by microRNAs (miRNAs) (4).

MiRNAs are essential post transcriptional gene expression regulators, that seem to control $30 \%$ and $90 \%$ of the human and mouse transcriptome (5). Gene expression is negatively 
regulated by miRNAs through translational repression or mRNA degradation (5). Importantly, the expression of many miRNAs is deregulated in premalignant and malignant lesions and this deregulation is relevant for patient diagnosis, prognosis and response to treatment (6). MiRNA-146a (7) and miRNA-150 (8) have been implicated in HPV induced carcinogenesis, where they are suggested to play an oncogenic role. Moreover, both miRNA-146a and miRNA150 are also involved in regulating immunological processes, including tumour associated inflammation (9-11).

MiRNA-146a expression is up-regulated by proinflammatory cytokines such as TNF- $\alpha$ and IL-1, through the nuclear factor-kappa B (NF-kB) pathway. MiRNA-146a subsequently represses the signal transducers IRAK1 and TRAF6, decreasing NF-kB activation and forming a negative feedback loop that attenuates inflammation (12). This is likely to be a prominent feature of many HPV driven malignancies, as NF- $\mathrm{kB}$ is often activated in these lesions (3). MiRNA-150 is involved in the differentiation and activation of lymphocytes (10-11), which are prominent mediators of immunity in the tumor microenvironment (13).

Our group recently reported the expression of important miRNAs involved in regulating inflammation in skin lesions caused by HPV16 in K14-HPV16 transgenic mice $(14,15)$. K14-HPV16 transgenic mice target all HPV16 oncogenes to keratinized epithelia, reproducing essential molecular and morphological aspects of HPV16 induced premalignant lesions and various types of cancer (16). Using the same model, we also reported that the anti-inflammatory drug celecoxib, a selective cycloxigenase-2 (COX-2) inhibitor, is able to up-regulate degranulation of $\mathrm{CD}^{+} \mathrm{T}$ cells in HPV 16 induced lesions (17). In the same experiment, celecoxib was also able to reduce the inflammation associated with HPV induced lesions and lesions' progression.

Now, we hypothesized that the effect of celecoxib may involve the regulation of miRNA-150 and miRNA-146a, both of which are associated with HPV induced clinical disease and regulation of immunity. In order to test this hypothesis, we proceeded to study both miRNAs' expression levels in skin lesions of celecoxib treated and control mice.

\section{Materials and Methods}

Animals. Generation of K14-HPV16 mice on a FVB/N background has been reported (9). The transgenic mouse strain was generously donated by Drs. Jeffrey Arbeit and Douglas Hanahan (University of California) through the USA National Cancer Institute Mouse Repository. The animal experiments were approved by the Universidade de Trás-os-Montes e Alto Douro Ethics Committee (10th of 2013) and the Portuguese General Veterinary Directorate (approval no. 0421/000/000/2014). The mice were housed and bred according to Portuguese (Decreto-Lei 113, August 7th) and European (EU Directive $2010 / 63 / \mathrm{EU})$ legislation, under controlled temperature $\left(23 \pm 2^{\circ} \mathrm{C}\right)$, lightdark cycle (12 h light followed by $12 \mathrm{~h}$ dark) and relative humidity
$(50 \pm 10 \%)$. Food and water were provided ad libitum. Genotyping was performed as previously described by our team $(14,15)$.

Experimental design. Thirty two female mice from 18 to 20 weeks old were divided into three experimental groups: Group A (HPV16 ${ }^{-/}$ untreated animals, $n=0)$, group $B\left(\mathrm{HPV} 16^{+/-}\right.$untreated animals, $\mathrm{n}=10$ ) and group $\mathrm{C}\left(\mathrm{HPV} 16^{+/-} \mathrm{CXB}\right.$-treated animals, $\left.\mathrm{n}=12\right)$. Celecoxib was administered orally for 6 consecutive weeks at $75.0 \mathrm{mg} / \mathrm{kg} / \mathrm{day}$. All surviving mice were humanely euthanized at 24 to 26 weeks old. Matched chest skin samples (approximately $4 \mathrm{~cm}^{2}$ ) were collected for histological analysis and miRNA quantification.

Histological analysis. Skin samples were fixated in $10 \%$ formalin for 48 hours, dehydrated through graded alcohols and xylene, and were paraffin embedded using an automatic STP 120 processor (Thermo Scientific, Waltham, USA). Two $\mu \mathrm{m}$ thick sections were stained with haematoxylin-eosin (H\&E) for histological evaluation on light microscopy. Skin samples were histologically classified as normal skin, epidermal hyperplasia and epidermal dysplasia.

MicroRNA isolation. MiRNAs isolation was performed according to Santos et al. (18). Firstly, total RNA was extracted using the TripleXtractor reagent (Grisp ${ }^{\circledR}$, Porto, Portugal), and subsequently the fraction of miRNA was isolated with a chloroform solution (Merck ${ }^{\circledR}$, Darmstadt, Germany). MiRNAs were then purified using the commercial kit GRS microRNA Kit (Grisp ${ }^{\circledR}$, Porto, Portugal) (19). MiRNA samples were kept at $-80^{\circ} \mathrm{C}$ until further use.

Complementary DNA synthesis. MiRNA samples were used as templates for complementary DNA (cDNA) synthesis using a TaqMan ${ }^{\circledR}$ MicroRNA Reverse Transcription Kit (Applied Biosystems ${ }^{\circledR}$, USA) and sequence specific stem-loop reverse transcription primers for miRNA-150, miRNA-146a and for small nucleolar RNA-202 (snoRNA-202). The amplification conditions were as follows: $30 \mathrm{~min}$ at $15^{\circ} \mathrm{C}, 52 \mathrm{~min}$ at $42^{\circ} \mathrm{C}$ and finally $10 \mathrm{~min}$ at $85^{\circ} \mathrm{C}$. cDNA was further used as template for quantitative realtime PCR (qPCR).

Quantitative real-time PCR. Each miRNA's expression was assessed by qPCR using a StepOneTM qPCR Real-Time PCR machine. The reactions were performed in a 48 -well plate. For each reaction $1 X$ TaqMan ${ }^{\circledR}$ Fast Advanced Master Mix (Applied Biosystems ${ }^{\circledR}$, Waltham, USA) was added to $1 \mathrm{X}$ probes (TaqMan ${ }^{\circledR}$ miRNA Expression Assays, miRNA-150: 000473, miRNA-146a: 000468, snoRNA-202: 001232, Applied Biosystems ${ }^{\circledR}$, Waltham, USA), making cDNA sample with a total volume of $10 \mu$ l. In order to normalize the results, snoRNA-202 was used as an endogenous control. This endogenous control was also previously tested by our group $(14,15)$. Quantification of miRNAs was performed in duplicate and negative control lacking cDNA was also included in all reactions. The thermal cycling conditions were as follows: One cycle of $10 \mathrm{~min}$ at $95^{\circ} \mathrm{C}$ followed by 45 cycles of 15 seconds at $95^{\circ} \mathrm{C}$ and $1 \mathrm{~min}$ at $60^{\circ} \mathrm{C}$. Data analysis was made using StepOne $^{\mathrm{TM}}$ Sofware v2.2 (Applied Biosystems ${ }^{\circledR}$, Waltham, USA) with the same conditions set for each plate, baseline and threshold, in order to generate threshold cycle $(\mathrm{Ct})$ values for miRNA-150, miRNA-146a and snoRNA-202 in each sample.

Statistical analysis. Statistical analysis was performed using the statistical software SPSS for Windows (Version 18.0) (IBM ${ }^{\circledR}$ SPSS ${ }^{\circledR}$, Armonk, USA). Mann-Whitney's $U$-test was used in order to evaluate statistical differences in normalized relative expression 


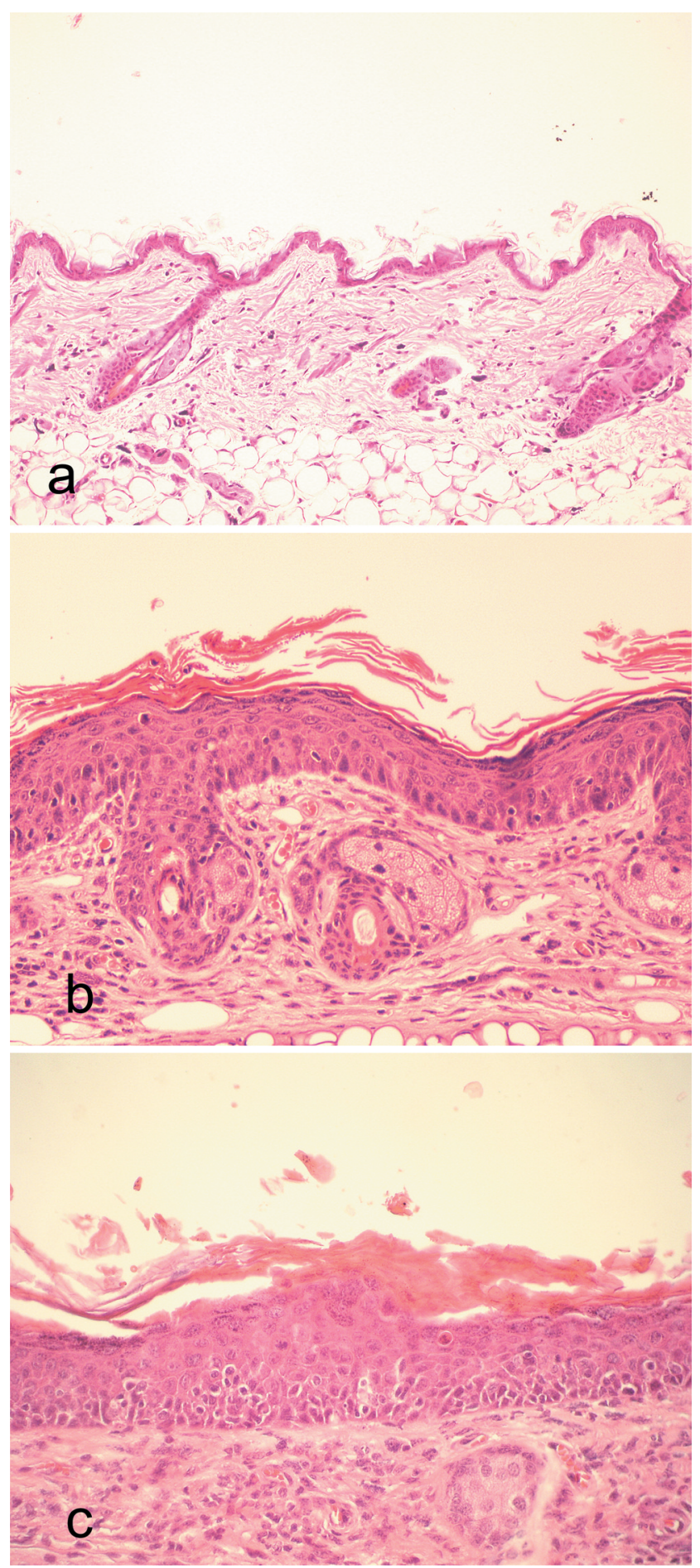

Figure 1. Histopathological changes induced by HPV16 oncogenes in FVB/n mice, H\&E. a: Normal skin histology, x40, b: - Epidermal hyperplasia and hyperkeratosis, $\times 100$, c: Epidermal dysplasia, $\times 100$.

$(-\Delta \mathrm{Ct})$ of miRNA-146a or miRNA-150 among different groups. Results were considered statistically significant when $p$-values were less than 0.05 .

\section{Results}

One subject from group B (HPV16 ${ }^{+/-}$untreated mice) and 3 from group C (HPV $16^{+/-}$mice treated with celecoxib) died during the experimental period $(10.0 \%$ and $25.0 \%$, respectively). No mortality $(0.0 \%)$ was observed in negative control group A (HPV $16^{-/-}$untreated mice).

Wild type animals (group A) showed normal skin histology, while transgenic mice (groups B and C) showed epidermal hyperplasia (100.0\% incidence) and, in some cases, multifocal dysplasia (Figure 1). A number of $33.3 \%$ of surviving animals from group $\mathrm{B}\left(\mathrm{HPV}^{+/-}\right.$untreated) and $11.1 \%$ of surviving animals from group $\mathrm{C}\left(\mathrm{HPV}^{+/-}\right.$treated with celecoxib) showed multifocal epidermal dysplasia.

We then studied the expression levels of two miRNAs, miRNA-146a and miRNA-150. Implicated in progression of HPV induced lesions and in regulation of innate and adaptive immunity. Untreated HPV $16^{+/-}$mice (group B) showed higher levels of expression of miRNA-146a $(p<0.05)$ and miRNA-150 $(p<0.05)$, compared with age- and sex-matched wild type mice (group A) (Figures 2 and 3). Celecoxib further increased expression levels of miRNA-146a $(p=0.56)$ in celecoxib-treated $\mathrm{HPV} 16^{+/-}$mice (group C) when compared with untreated HPV $16^{+/-}$mice (group B) (Figure 4). Celecoxib-treated mice also showed significantly higher expression levels of miRNA-150 $(p<0.05)$ compared to matched untreated mice (groups B and C) (Figure 5).

\section{Discussion}

Genetically-modified animals, such as K14-HPV16 mice, are useful models for studying the immune response associated with multi step carcinogenesis induced by HPV. Several other animal models are available for studying papillomavirusinduced lesions, such as rabbits, cattle and laboratory rodents susceptible to spontaneous or experimental papillomaviral infections $(20,21)$, as well as xenograft models and genetically-modified mice (22). Although such models are useful for many purposes, xenografts commonly rely on immunocompromised mice, and their suitability for immunological studies is limited. Other models based on different mammals and their respective papillomaviruses need to be used carefully since they are limited from the differences between the viruses they host and HPV (e.g. bovine papillomavirus or cottontail rabbit papillomavirus). K14-HPV16 mice avoid these limitations as they express HPV16 early genes and possess a fully-functional immune system, providing a reliable and versatile model for modulating the tumour associated immune response in HPV16 induced lesions. Our group has already studied the expression of two microRNAs miRNA-21 and miRNA-155 which are related to the inflammatory process in this model (14-15). More recently, we showed that a relatively high dose 


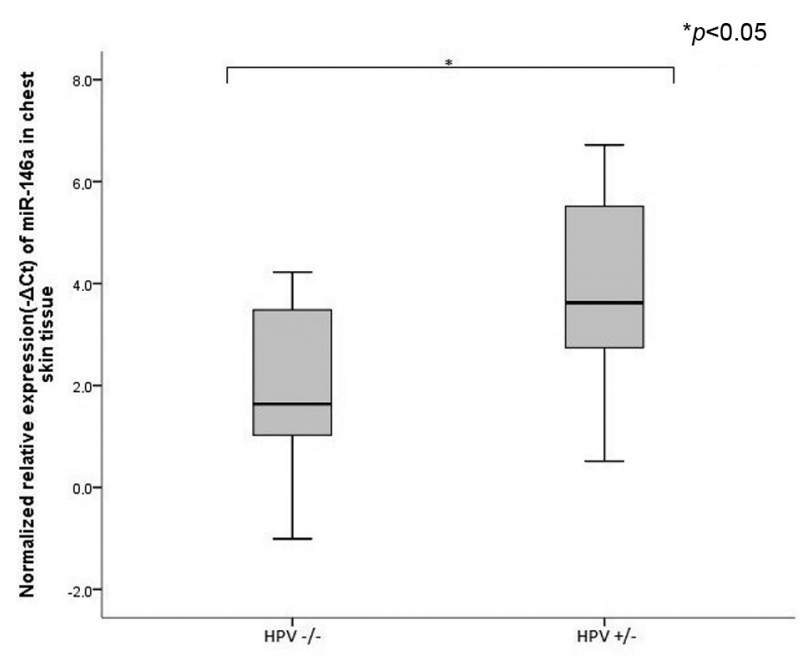

Figure 2. Normalized relative expression of miRNA-146a in chest skin tissue of wild-type mice $\left(\mathrm{HPV}^{-1-}\right)$ and K14-HPV16 transgenic mice $\left(\mathrm{HPV}^{+/-}\right)$. MiRNA-146a is up-regulated in chest skin lesions of $\mathrm{HPV}^{+/-}$ mice when compared to normal chest skin of $\mathrm{HPV}^{-/-}$mice $\left({ }^{*} p<0.05\right)$.

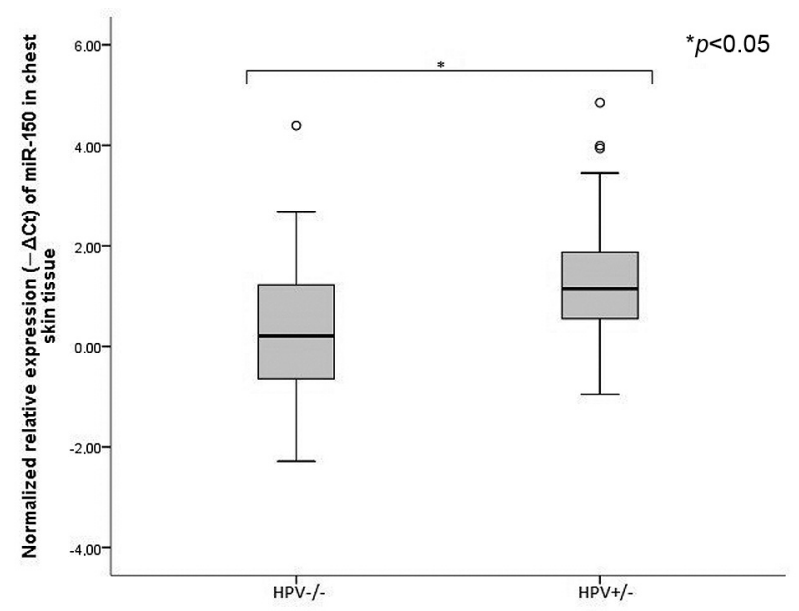

Figure 3. Normalized relative expression of miRNA-150 in chest skin tissue of wild type mice $\left(\mathrm{HPV}^{--}\right)$and K14-HPV16 transgenic mice $\left(\mathrm{HPV}^{+/-}\right)$. MiRNA-150 is up-regulated in chest skin lesions of $\mathrm{HPV}^{+/-}$ mice when compared to normal chest skin of $H P V^{-/-}$mice. $\left({ }^{*} p<0.05\right)$.

(124 mg/kg/day) of celecoxib, a selective COX-2 inhibitor, promotes degranulation of CD8+ T cells in this model (17), while ptaquiloside, a natural immunosuppresive agent from Pteridium spp., down-regulates it (23).

In the present work, we chose to use a lower and potentially safer celecoxib dose $(75 \mathrm{mg} / \mathrm{kg} /$ day $)$ compared

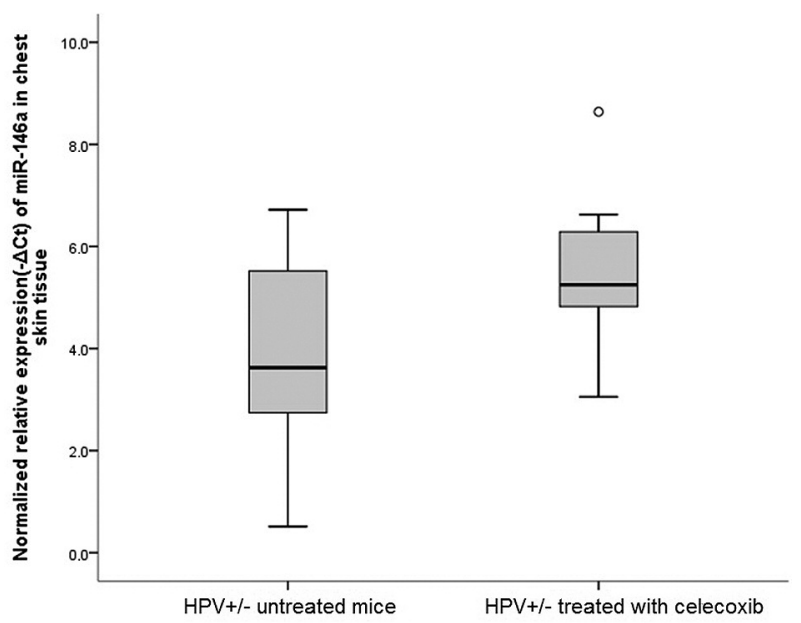

Figure 4. Normalized relative expression of miRNA-146a in chest skin lesions of untreated K14-HPV16 transgenic mice $\left(\mathrm{HPV}^{+/-}\right)$and $\mathrm{HPV}^{+/-}$ mice treated with celecoxib. MiRNA-146a is up-regulated in chest skin lesions of $\mathrm{HPV}^{+/-}$mice treated with celecoxib when compared to untreated $\mathrm{HPV}^{+/-}$mice $(p=0.056)$.

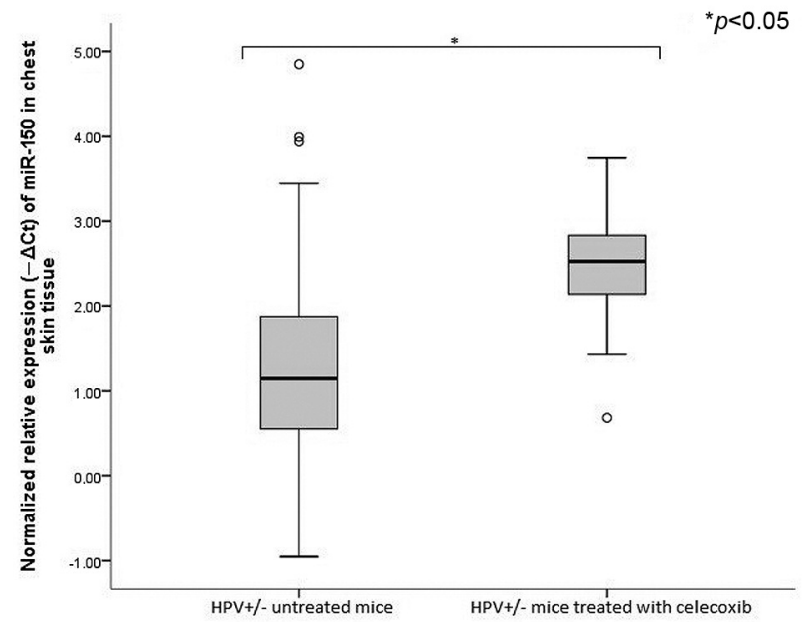

Figure 5. Normalized relative expression of miRNA-150 in chest skin lesions of untreated K14-HPV16 transgenic mice $\left(H P V^{+/-}\right)$and $H P V^{+/-}$ mice treated with celecoxib. MiRNA-150 is up-regulated in chest skin lesions of $\mathrm{HPV}^{+/-}$mice treated with celecoxib when compared to untreated $\mathrm{HPV}^{+/-}$mice $(* p<0.05)$.

with our previous study (124 mg/kg/day), since concerns have been raised concerning its cardiovascular toxicity (24). The celecoxib dose employed in the previous study completely abrogated dysplastic lesions. In this study, celecoxib at a lower dose of $75 \mathrm{mg} / \mathrm{kg} /$ day reduced the incidence of epidermal dysplasia $(11.1 \%$ vs. $33.3 \%$ in 
untreated group), but did not eliminate it, thus suggesting a possible dose related effect. The current dose of celecoxib still induced a high mortality rate $(25.0 \% \mathrm{vs} .10 .0 \%$ in untreated group), presumably associated with the intrinsic frailty of this particular mouse strain.

The multi-step process of carcinogenesis observed in K14HPV16 mice is accompanied by increasingly severe inflammation and angiogenesis, particularly when hyperplastic lesions progress to dysplasia (25). As expected, celecoxib, reduced the incidence of epidermal dysplasia and associated dermal inflammation. This was in accordance to a significant increase in the expression level of miRNA$146 \mathrm{a}$, which has recently been pointed as a key regulator of the immune system (26).

The expression of miRNA-146a is up-regulated by the proinflammatory transcription factor $\mathrm{NF}-\mathrm{kB}$, as reviewed by Ma et al. (27). As mentioned above, miRNA-146a is part of a negative feedback loop that controls excessive and tissue damaging inflammation, by repressing signal transducers IRAK1 and TRAF6 (12). These are essential mediators of the NF-KB signaling pathway, and their repression prevents the activation $\mathrm{NF}-\mathrm{kB}$, thus reducing proinflammatory signaling. NF-kB is frequently activated in HPV induced malignancies and many of these lesions show significant associated inflammation (3). This is also the case with K14HPV16 mice, where multistep carcinogenesis is associated with progressive severe inflammation (13).

The present results, showing increased expression of miRNA-146a in the skin lesions of $\mathrm{HPV} 16^{+/-}$mice, compared with normal skin samples from HPV $16^{-/-}$mice, are in line with the known functions of miRNA-146a. As inflammation develops, miRNA-146a is likely up-regulated as part of the normal cellular response that limits inflammatory processes $(9,12)$.

Treatment with celecoxib further increased the expression of miRNA-146a in transgenic mice. This increase very nearly reaches the significance level, suggesting that celecoxib may modulate miRNA-146a expression in this model. This hypothesis agrees with recent reports from different groups, showing that curcumin, another antiinflammatory compound, is able to up-regulate miRNA-146a expression in different neoplastic cell lines (28-29). Additionally, Cornett and Lutz reported that miRNA-146a targets COX-2, binding to its mRNA through a single miRNA binding site located in the 3'-UTR and effectively down-regulating its expression in lung cancer cells (30). Taken together, these data suggest that celecoxib increased miRNA-146a levels in HPV16 induced lesions and therefore reducing the incidence of dysplasia in our model.

The second miRNA studied in the present experiments was miRNA-150. The role of miRNA-150 in HPV induced carcinogenesis is still poorly investigated. However, this miRNA is known to be up-regulated in cervical cancer, where it promotes cell growth and survival by targeting FOXO4 (8). HPV16 ${ }^{+/-}$mice showed significantly increased miRNA-150 levels compared with HPV $16^{-/}$mice, which is in line with these previous studies, and supports the hypothesis that miRNA-150 acts as an oncomiR in HPV related malignancies. The expression of miRNA-150 seems to be positively regulated by NF-kB (31), a transcription factor commonly activated in HPV related cancers (3). Recently, miRNA-150 was also shown to down-regulate arrestin beta 2, leading to NF-kB inhibition (32), which suggests the existence of a negative feedback loop. Here, celecoxib treated animals showed increased miRNA-150 levels compared with matched untreated mice, suggesting that celecoxib may act through miRNA-150 to down-regulate NF-kB signalling through this negative feedback loop.

Taken together, these results suggest that the antitumoural action of celecoxib over HPV induced lesions may be, at least in part, mediated through miRNA-146a and miRNA150 up-regulation. Further studies need to be made to clarify the mechanisms whereby celecoxib regulates miRNA-150, and affects other components of the immune reaction to HPV16 induced lesions.

\section{Acknowledgements}

This study was funded by Liga Portuguesa Contra o Cancro, by the Research Center of the Portuguese Institute of Oncology of Porto (CI-IPOP 37-2016), by project POCI-01-0145-FEDER-006939 (Laboratory for Process Engineering, Environment, Biotechnology and Energy - LEPABE), by project POCI-01-0145-FEDER-006958 and UID/AGR/04033/2013. It was funded by FEDER funds through COMPETE2020 - Programa Operacional Competitividade e Internacionalização (POCI) and by national funds through FCT, Fundação para a Ciência e a Tecnologia. Rui M. Gil da Costa was funded by grant number SFRH/BPD/85462/2012 from FCT, by the Portuguese Government and by the Social European Fund.

\section{References}

1 Zandberg DP, Bhargava R, Badin S and Cullen KJ: The role of human papillomavirus in nongenital cancers. CA Cancer J Clin 63(1): 57-81, 2013.

2 Venuti A, Paolini F, Nasir L, Corteggio A, Roperto S, Campo MS and Borzacchiello G: Papillomavirus E5: the smallest oncoprotein with many functions. Mol Cancer 10: 140, 2011.

3 Gil da Costa RM, Bastos MMSM, Medeiros R and Oliveira PA: The NFkB signalling pathway in papillomavirus-induced lesions: friend or foe? Anticancer Res 36: 2073-2083, 2016.

4 Guo L, Zhang Y, Huang F, Li J and Wang S: MicroRNAs, TGF$\beta$ signalling, and the inflammatory microenvironment in cancer. Tumour Biol 37: 115-125, 2016.

5 Huang Y, Shen XJ, Zou Q, Wang SP, Tang SM, Zhang GZ: Biological functions of microRNAs: a review. J Physiol Biochem 67: 129-139, 2011.

6 Reddy KB: MicroRNA (miRNA) in cancer. Cancer Cell Int 15: $38,2015$. 
7 Wang X, Tang S, Le S-Y, Lu R, Rader JS, Meyers C and Zheng $\mathrm{ZM}$ : Aberrant expression of oncogenic and tumor-suppressive microRNAs in cervical cancer is required for cancer cell growth. PLoS ONE 3(7): e2557, 2008.

8 Li J, Hu L, Tian C, Lu F, Wu J and Liu L: microRNA-150 promotes cervical cancer cell growth and survival by targeting FOXO4. BMC Mol Biol 16(1): 24, 2015.

9 Williams AE, Perry MM, Moschos SA, Larner-Svensson HM and Lindsay MA: Role of miRNA-146a in the regulation of the innate immune response and cancer. Biochem Soc Trans 36: 1211-1215, 2008.

10 Trifari S, Pipkin ME, Bandukwala HS, Aijo T, Bassein J, Chen R, Martinez GM and Rao A: MicroRNA-directed program of cytotoxic CD8+ T-cell differentiation. Proc Natl Acad Sci 110(46): 18608-18613, 2013.

11 He Y, Jiang X and Chen J: The role of miR-150 in normal and malignant hematopoiesis. Oncogene 33: 3887-3893, 2014.

12 Taganov KD, Boldin MP, Chang K-J and Baltimore D: NF-kBdependent induction of microRNA-146, an inhibitor targeted to signalling proteins of innate immune responses. PNAS 103: 12481-12486, 2016.

13 de Visser KE, Korets LV and Coussens LM: De novo carcinogenesis promoted by chronic inflammation is $\mathrm{B}$ lymphocyte dependent. Cancel Cell 7: 411-423, 2005.

14 Paiva I, Gil da Costa RM, Ribeiro J, Sousa H, Bastos MM, Faustino-Rocha A, Lopes C, Oliveira PA and Medeiros R: MicroRNA-21 expression and susceptibility to HPV-induced carcinogenesis - role of microenvironment in K14-HPV16 mice model. Life Sci 128: 8-14, 2015.

15 Paiva I, Gil da Costa RM, Ribeiro J, Sousa H, Bastos M, Rocha AF, Oliveira PA and Medeiros R: A Role for MicroRNA-155 Expression in Microenvironment Associated to HPV-Induced Carcinogenesis in K14-HPV16 Transgenic Mice. PLoS One 10(1): e0116868, 2015.

16 Arbeit JM, Munger K, Howley PM and Hanahan D: Progressive squamous epithelial neoplasia in K14-human papillomavirus type 16 transgenic mice. J Virol 68(7): 4358-4368, 1994.

17 Santos C, Neto T, Ferreirinha P, Sousa H, Ribeiro J, Bastos MM, Faustino-Rocha AI, Oliveira PA, Medeiros R, Vilanova M and Gil da Costa RM: Celecoxib promotes degranulation of $\mathrm{CD}^{+} \mathrm{T}$ cells in HPV-induced lesions of K14-HPV16 transgenic mice. Life Sci 157: 67-73, 2016.

18 Santos JI, Teixeira AL, Dias F, Maurício J, Lobo F, Morais A and Medeiros R: Influence of peripheral whole-blood microRNA-7 and microRNA-221 high expression levels on the acquisition of castration-resistant prostate cancer: Evidences from in vitro and in vivo studies. Tumor Biol 35: 7105-7113, 2014.

19 Teixeira AL, Dias F, Ferreira M, Gomes M, Santos JI, Lobo F, Mauricio J, Machado JC and Medeiros R: Combined influence of $\mathrm{EGF}+61 \mathrm{G}>\mathrm{A}$ and $\mathrm{TGFB}+869 \mathrm{~T}>\mathrm{C}$ functional polymorphisms in renal cell carcinoma progression and overall survival: The link to plasma circulating MiR-7 and MiR-221/222 Expression. PLoS One 10: 1-15, 2015.
20 Gil da Costa RM and Medeiros R: Bovine papillomavirus: opening new trends for comparative pathology. Arch Virol 159: 191-198, 2014.

21 Gil da Costa RM, Peleteiro MC, Pires MA and DiMaio D: An update on canine, feline and bovine papillomaviruses. Transbound Emerg Dis (in press), 2016. [Epub ahead of print]

22 Doorbar J: Model systems of human papillomavirus-associated disease. J Pathol 238(2): 166-179, 2016.

23 Santos C, Ferreirinha P, Sousa H, Ribeiro J, Bastos MM, Neto T, Oliveira PA, Medeiros R, Vilanova M and Gil da Costa RM: Ptaquiloside from bracken (Pteridium spp.) inhibits tumourinfiltrating CD8+ T cells in HPV-16 transgenic mice. Food Chem Toxicol 97: 277-285, 2016.

24 Nurmohamed MT: Therapy: cardiovascular safety of celecoxib, naproxen and ibuprofen. Nat Rev Rheumatol 13: 136-138, 2017.

25 Hanahan D, Christofori G, Naik P and Arbeit J: Transgenic mouse models of tumour angiogenesis: the angiogenic switch, its molecular controls, and prospects for preclinical therapeutic models. Eur J Cancer 32A: 2386-2393, 1996.

26 Sheppard HM, Verdon D, Brooks AES, Feisst V, Ho Y-Y J, Lorenz N, Fan V, Birch NP, Didsbury A and Dunbar PR: MicroRNA regulation in human $\mathrm{CD} 8^{+} \mathrm{T}$ cell subsets - cytokine exposure alone drives miR-146a expression. J Transl Med 12: 292, 2014.

27 Ma X, Buscaglia LEB, Barker JR and Li Y: MicroRNAs in NFkB signaling. J Mol Cell Biol 3: 159-166, 2011.

28 Ali S, Ahmad A, Aboukameel A, Ahmed A, Bao B, Banerjee A, Philip PA and Sarkar FH: Deregulation of miR-146a expression in a mouse model of pancreatic cancer affecting EGFR signaling. Cancer Lett 35: 134-142, 2015.

$29 \mathrm{Wu} \mathrm{H}$, Liu Q, Cai T, Chen YD and Wang ZE: Induction of microRNA-146a is involved in curcumin-mediated enhancement of temozolomide cytotoxicity against human glioblastoma. Mol Med Rep 12: 5461-5466, 2015.

30 Cornett AL and Lutz CS: Regulation of COX-2 expression by miR-146a in lung cancer cells. RNA 20: 1419-1430, 2014.

31 Ghose J and Bhattacharyya NP: Transcriptional regulation of microRNA-100, -146a, and -150 genes by p53 and NFkappaB p65/RelA in mouse striatal STHdh(Q7)/ Hdh(Q7) cells and human cervical carcinoma HeLa cells. RNA Biol 12: 457-477, 2015.

32 Sang W, Wang Y, Zhang C, Zhang D, Sun C, Niu M, Zhang Z, Wei X, Pan B, Chen W, Yan D, Zeng L, Loughran TP Jr and Xu $\mathrm{K}$ : MiR-150 impairs inflammatory cytokine production by targeting ARRB-2 after blocking CD28/B7 costimulatory pathway. Immunol Lett 172: 1-10, 2016.

Received March 11, 2017

Revised April 23, 2017

Accepted April 24, 2017 